\title{
Acute elevation of circulating fatty acids impairs downstream insulin signalling in rat skeletal muscle in vivo independent of effects on stress signalling
}

\author{
Georgia Frangioudakis ${ }^{1}$ and Gregory J Cooney ${ }^{1,2}$ \\ ${ }^{1}$ Diabetes and Obesity Research Program, Garvan Institute of Medical Research, St Vincent's Hospital, 384 Victoria Street, Darlinghurst, Sydney 2010, \\ New South Wales, Australia \\ ${ }^{2}$ Department of Medicine, St Vincent's Medical School, University of New South Wales, Sydney 2052, New South Wales, Australia \\ (Correspondence should be addressed to G J Cooney; Email: g.cooney@garvan.org.au)
}

\begin{abstract}
The aim of this study was to examine the effect of an acute, physiological increase in plasma free fatty acid (FFA) on initial signalling events in rat red quadriceps muscle (RQ). Male Wistar rats received a 7\% glycerol (GLYC) or 7\% Intralipid/heparin (LIP) infusion for $3 \mathrm{~h}$, after which they were either killed or infused with insulin at a rate of $0.5 \mathrm{U} / \mathrm{kg}$ per h for $5 \mathrm{~min}$, before RQ collection. Plasma FFAs were elevated to $\sim 2 \mathrm{mM}$ in the LIP rats only. Insulin-stimulated insulin receptor (IR) Tyr1162/Tyr1163 phosphorylation and IR substrate (IRS)-1 Tyr612 phosphorylation were increased at least twofold over basal in GLYC rats with insulin and this increase was not significantly impaired in the LIP rats. However, there was no insulin-stimulated protein kinase B (PKB) Ser473 or glycogen synthase kinase (GSK)-3 $\beta$ Ser9 phosphorylation in the LIP rats,
\end{abstract}

compared with at least a twofold increase over basal in GLYC rats for both proteins. c-Jun $\mathrm{N}$-terminal kinase, inhibitor of $\kappa$ kinase $\beta$ and inhibitor of nuclear factor- $\kappa \mathrm{B}$ phosphorylation and total protein expression, as well as Ser307-IRS-1 phosphorylation, were not altered by lipid infusion compared with GLYC infusion. These data indicate that acute, physiological elevation in FFA has a greater impact on insulin signalling downstream of IR and IRS-1, at the level of PKB and GSK-3 $\beta$, and that under these conditions stress signalling pathways are not significantly stimulated. Decreased PKB and GSK-3 $\beta$ phosphorylation in RQ may therefore be primary determinants of the reduced insulin action observed in situations of acute FFA oversupply.

Journal of Endocrinology (2008) 197, 277-285

\section{Introduction}

The accretion of triglycerides (TGs) and various lipid intermediates in non-adipose tissue such as liver and muscle correlates strongly with reduced insulin action in these tissues (Storlien et al. 1991, Pan et al. 1997). We have recently shown that chronic feeding of a high saturated or polyunsaturated fat diet to rats impairs insulin action, and is associated with increased skeletal muscle TG content and reduced phosphorylation of insulin receptor substrate (IRS)-1 and protein kinase $\mathrm{B}$ (PKB) under conditions of physiological insulin elevation (Frangioudakis et al. 2005). Insulin resistance can also be induced by an acute infusion of lipid to elevate circulating fatty acid (FA; Chalkley et al. 1998, Ye et al. 2002). The degree of insulin resistance in acute lipid-infused rats can be similar to that observed in chronic high-fat-fed rats, and consequently it has been suggested that the lipid-induced insulin resistance in these models may share a similar mechanism. Studies assessing signalling after acute lipid infusion in rodents and humans have not always produced consistent results. For example, in skeletal muscle from rats, defective insulin action due to acute lipid infusion has been reported to occur in conjunction with

reduced insulin-stimulated IRS-1-associated phosphatidylinositol-3-kinase (PI3-K) activity and reduced insulinstimulated IRS-1 tyrosine phosphorylation in one study, although PKB phosphorylation was not measured (Griffin et al. 1999). In another study, PKB Ser473 phosphorylation was reduced but upstream signalling was not assessed (Ye et al. 2002). In humans, impaired skeletal muscle IRS-1 tyrosine phosphorylation and associated PI3-K activity has been described, but PKB phosphorylation was unchanged (Kruszynska et al. 2002).

Variable study conditions used to induce insulin resistance and provide an insulin stimulus may have influenced the reported differences in insulin signalling thought to represent the in vivo effect of elevated FA in insulin-resistant states. The levels of FA attained in the rodent studies described above (Griffin et al. 1999, Ye et al. 2002) were very high, in the range of 3-5 mM. FAs at this concentration are not physiological and could conceivably be directly deleterious to the normal cellular environment by destabilising membranes (Newsholme \& Leech 1983). Furthermore, extended euglycaemic-hyperinsulinaemic clamps (Ye et al. 2002) and/or i.v. bolus insulin injections (Griffin et al. 1999) may not be ideal methods for examining the 
initial activation of the insulin signalling pathway that is thought to be critical for optimal insulin action.

It also remains unclear whether FAs themselves have a direct effect on insulin signalling to impair insulin action or whether the observed defects are a consequence of a systemic adaptation to excess lipid availability. Altered adipocytokine secretion (Matsuzawa et al. 1999), for example, can lead to the activation of inflammatory stress signalling pathways that have recently been suggested to be mediators of the insulin resistance seen in diabetes and obesity. Specifically, it has been postulated that excess FA can activate the c-Jun N-terminal kinase (JNK; Hirosumi et al. 2002) and inhibitor of $\kappa \mathrm{B}$ kinase (IKK)/nuclear factor $-\kappa \mathrm{B}(\mathrm{NF}-\kappa \mathrm{B}$; Kim et al. 2001, Yuan et al. 2001) pathways leading to inhibitory phosphorylation of insulin signalling intermediates (Aguirre et al. 2000, Gao et al. 2002, Le Marchand-Brustel et al. 2003). The extent to which this happens in muscle with lipid infusion has not been determined.

The aim of this study was to examine the consequences of an acute, physiological elevation of plasma FA on components of the insulin and stress signalling pathways in vivo in skeletal muscle, with or without an insulin infusion similar to the beginning of a euglycaemic-hyperinsulinaemic clamp. Our hypotheses were as follows: 1) changes in insulin signalling following acute lipid infusion may differ to those reported following chronic high-fat feeding and 2) stimulation of stress signalling may play a role in any observed impairments. We show that defective insulin signalling in this model originated downstream of the IR and IRS-1, at the level of PKB and its downstream target, glycogen synthase kinase (GSK)-3 $\beta$. This was not associated with stimulation of stress signalling intermediates.

\section{Materials and Methods}

\section{Experimental animals and dietary treatment}

All procedures were approved by the Garvan Institute/St Vincent's Hospital Animal Experimentation Ethics Committee and were in accordance with the National Health and Medical Research Council of Australia Guidelines on Animal Experimentation. Male Wistar rats $(\sim 300 \mathrm{~g}$ or 10 weeks of age) supplied from the Animal Resources Centre (Perth, Australia) were acclimatised in communal cages at $22 \pm 1{ }^{\circ} \mathrm{C}$ with a $12 \mathrm{~h}$ light: $12 \mathrm{~h}$ darkness cycle (lights on $0600 \mathrm{~h}$ ) for 1 week and had access to a standard chow diet (Gordon's Specialty Stock Feed, Sydney, Australia) and water ad libitum.

\section{Animal preparation}

After acclimatisation, rats were chronically cannulated via the right jugular vein and the left carotid artery under halothane (Fluothane; Cenvet Pty Ltd, NSW, Australia) inhalation anaesthesia (5\% induction, $2 \%$ maintenance) and the cannulae were exteriorised via a small incision at the back of the neck. Post-surgery recovery over a 7-day period was closely monitored with the measurement of food intake and body weight gain. The rats were handled daily to minimise stress and only those with fully recovered body weight were used for the study.

\section{Lipid infusion and insulin stimulation}

Rats were fasted $5 \mathrm{~h}$ prior to study and were randomly assigned to be infused with either a 7\% Intralipid/heparin infusion (LIP) for $3 \mathrm{~h}$ to induce insulin resistance or a $7 \%$ glycerol infusion (GLYC) for $3 \mathrm{~h}$ as control. The protocol used in this study was based on Ye et al. (2004), with an adjustment in the amount of TG emulsion being infused to limit the elevation in free FAs (FFAs) to within a range that may be seen clinically in type 2 diabetic patients (Fraze et al. 1985, Chen et al. 1987). The rate of infusion was $2 \mathrm{ml} / \mathrm{h}$, with a concomitant heparin infusion of $40 \mathrm{U} / \mathrm{h}$ to aid in the lipolysis of the TG emulsion. Blood samples $(100 \mu \mathrm{l})$ were taken every 30 min during the $3 \mathrm{~h}$ LIP or GLYC infusions and every 2 min during the insulin infusion for the analysis of FFA and insulin concentrations. After the LIP or GLYC infusion, the rats were either killed with an i.v. overdose of sodium pentobarbitone (Nembutal; Cenvet Pty Ltd) and tissues rapidly collected (BASAL), or a subset from each group was stimulated with insulin at a rate of $0.5 \mathrm{U} / \mathrm{kg}$ per h for $5 \mathrm{~min}$ (INSULIN) before tissue collection. Red quadriceps skeletal muscle (RQ) was rapidly dissected, freeze-clamped with aluminium tongs pre-cooled in liquid nitrogen and stored at $-80{ }^{\circ} \mathrm{C}$ for subsequent analysis. Stress signalling results are from basal samples only; insulin signalling results are from both basal and insulin-stimulated samples.

\section{Metabolite measurements}

Plasma FFAs were determined spectrophotometrically using an enzymatic colorimetric method (NEFA-C kit; Wako Pure Chemical Industries, Osaka, Japan). Plasma insulin was determined by RIA using a rat-specific kit (Linco Research, St Charles, MO, USA). RQ skeletal muscle TGs were extracted using the method of Folch et al. (1957) and quantified using an enzymatic colorimetric method (GPOPAP reagent; Roche Diagnostics).

\section{Protein extraction}

RQ muscle was homogenised in an ice-cold solubilisation buffer containing $65 \mathrm{mM}$ Tris ( $\mathrm{pH} \mathrm{7 \cdot 4),} 150 \mathrm{mM} \mathrm{NaCl}$, $5 \mathrm{mM}$ EDTA, 1\% Nonidet P40, 0.5\% Na-deoxycholate, $0 \cdot 1 \%$ SDS, $10 \%$ GLYC, $1 \mu \mathrm{g} / \mathrm{ml}$ aprotinin, $1 \mu \mathrm{g} / \mathrm{ml}$ leupeptin, $10 \mathrm{mM} \mathrm{NaF}, 1 \mathrm{mM} \mathrm{Na}_{3} \mathrm{VO}_{4}$ and $1 \mathrm{mM}$ phenylmethylsulphonyl fluoride. The homogenate was solubilised for $2 \mathrm{~h}$ at $4{ }^{\circ} \mathrm{C}$ and then centrifuged at $12000 \mathrm{~g}$ for $15 \mathrm{~min}$ to remove insoluble material. Protein concentration of the supernatants was determined using the Bio-Rad protein assay (Bio-Rad Laboratories). 


\section{Immunoblot analyses}

Protein homogenates were prepared in Laemmli buffer (Laemmli 1970) and subjected to SDS-PAGE. To allow for quantification between blots, an in-house standard was also run on each gel. Proteins were separated on 6 or $7 \cdot 5 \%$ gels, transferred to polyvinylidenedifluoride (PVDF) membranes (Hybond-P; Amersham Biosciences) and blocked in 1\% BSA or $5 \%$ skim milk-Tris-buffered saline containing $0.025 \%$ Tween 20. The membranes were probed with the following primary antibodies that were mainly purchased from Cell Signaling Technology (Beverly, MA, USA), unless otherwise stated: anti-IR/insulin-like growth factor-I-pYpY1162/1163 (Biosource, Camarillo, CA, USA), anti-IR $\beta$ (BD Transduction Laboratories, San Diego, CA, USA), anti-IRS-1-pY612 (Biosource), anti-phospho (Ser307)-IRS-1 (Upstate Cell Signaling Solutions, Lake Placid, NY, USA), anti-IRS-1 (Upstate Cell Signaling Solutions), anti-phospho (Ser473)Akt, anti-Akt, anti-phospho (Ser21/9)-GSK-3 $\alpha / \beta$, antiGSK-3 $\beta$, anti-phospho (Thr183/Tyr185)-JNK, anti-JNK, anti-phospho (Ser176/180)-IKK $\alpha / \beta$, anti-IKK $\beta$, anti-phospho (Ser32)-I $\kappa \mathrm{B} \alpha$ or anti-I $\kappa \mathrm{B} \alpha$. The membranes were then incubated with donkey anti-rabbit-horseradish peroxidase (HRP) or protein A-HRP secondary antibody and bands detected by chemiluminescence (Perkin-Elmer Life Sciences, Boston, MA, USA) after exposure to film (Fuji Photo Film Co, Tokyo, Japan). The membranes were probed with phosphorylated antibodies first, then stripped and re-probed with the corresponding total antibodies. Films were subsequently scanned and the densities of bands of interest were quantified using IPLab Gel software (Signal Analytics Corporation, Vienna, VA, USA).

\section{Statistical analysis}

Results are presented as mean \pm s.E.M. Data were analysed by factorial ANOVA followed by Fisher's PLSD post hoc tests. Statistical calculations were performed using a commercial software package (StatView 5·0; SAS Institute Inc., Cary, NC, USA). Differences were considered significant at $P<0 \cdot 05$.

\section{Results}

\section{General metabolic parameters}

In order to examine the effect of an acute elevation of plasma FAs on components of the insulin and stress signalling pathways, rats were infused with LIP or GLYC as a control for $3 \mathrm{~h}$, with or without an extra 5-min insulin infusion at the end. The body weight of all rats used in this study was not significantly different (GLYC, 338 \pm 6.4 g; LIP, $337 \pm 8.6$ g; $n=12-13$ rats/group). Plasma insulin levels during the LIP or GLYC infusions did not vary from basal levels and were not statistically different from each other (Fig. 1A). With exogenous insulin infusion at $0.5 \mathrm{U} / \mathrm{kg}$ per $\mathrm{h}$ for $5 \mathrm{~min}$,
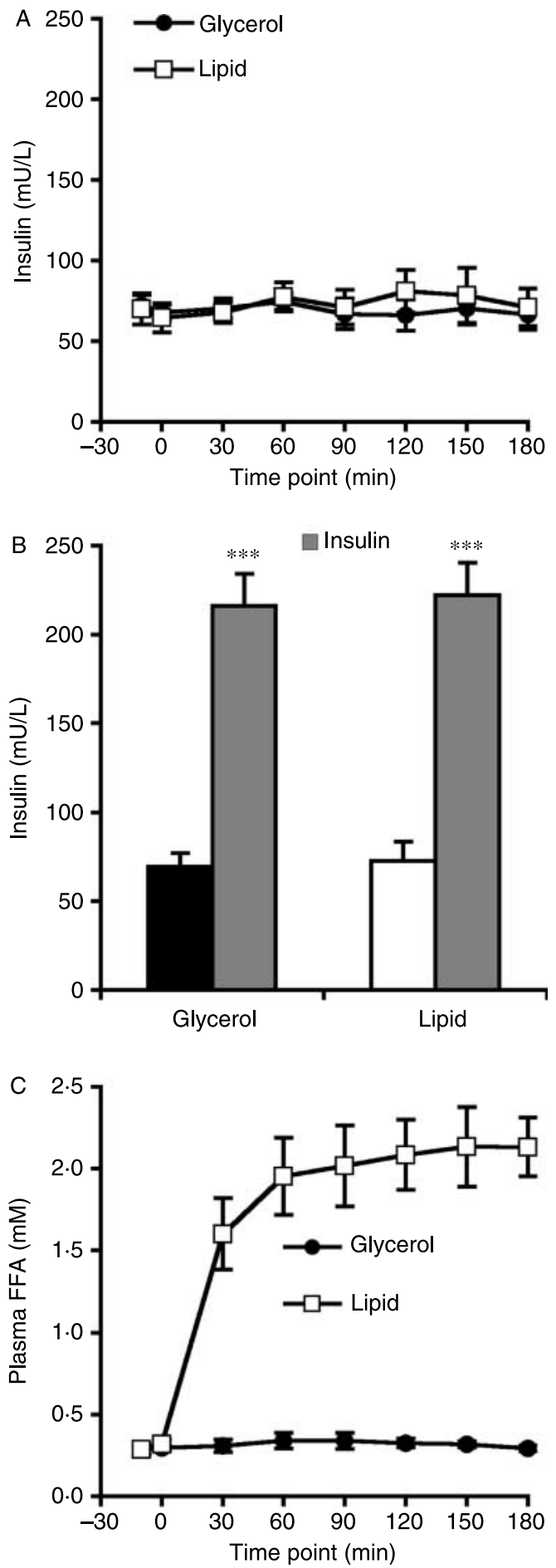

Figure 1 Time course of plasma insulin and FFA concentrations in glycerol and lipid-infused rats. Plasma insulin levels during infusion with Intralipid/heparin or glycerol for (A) $3 \mathrm{~h}$ and (B) after exogenous insulin at $0.5 \mathrm{U} / \mathrm{kg}$ per $\mathrm{h}$ for $5 \mathrm{~min}$. (C) Plasma FFA concentrations in the glycerol and lipid-infused rats. Values are mean \pm S.E.M. of $n=6-7$ rats/group. ${ }^{* * *} P<0 \cdot 001$ versus basal. 
circulating insulin was increased to a similar degree in both groups of rats, approximately threefold over basal (Fig. 1B). Plasma FFAs were significantly elevated in the LIP rats compared with the GLYC-infused rats $(P<0 \cdot 0001)$. Circulating FFAs increased to $\sim 2 \mathrm{mM}$ in the lipid-infused rats by $60 \mathrm{~min}$ after the start of infusion, after which the levels remained constant (Fig. 1C). Plasma FFAs were not significantly changed with the GLYC infusion (Fig. 1C).

\section{IR activation}

Basal levels of phosphorylation of the IR at Tyr1162 and Tyr1163 residues (autophosphorylation sites required for complete kinase activation; Tavare \& Siddle 1993) were not significantly different between the GLYC and lipid-infused rats (Fig. 2A and B). Insulin stimulation at $0.5 \mathrm{U} / \mathrm{kg}$ per $\mathrm{h}$ for 5 min resulted in a similar level of Tyr1162/Tyr1163 phosphorylation of the IR in both the GLYC and lipidinfused rats, approximately twofold higher than basal (Fig. 2A and $\mathrm{B}$ ). Total IR $\beta$ protein expression was not significantly affected by infusion with GLYC, lipid or insulin (Fig. 2B).
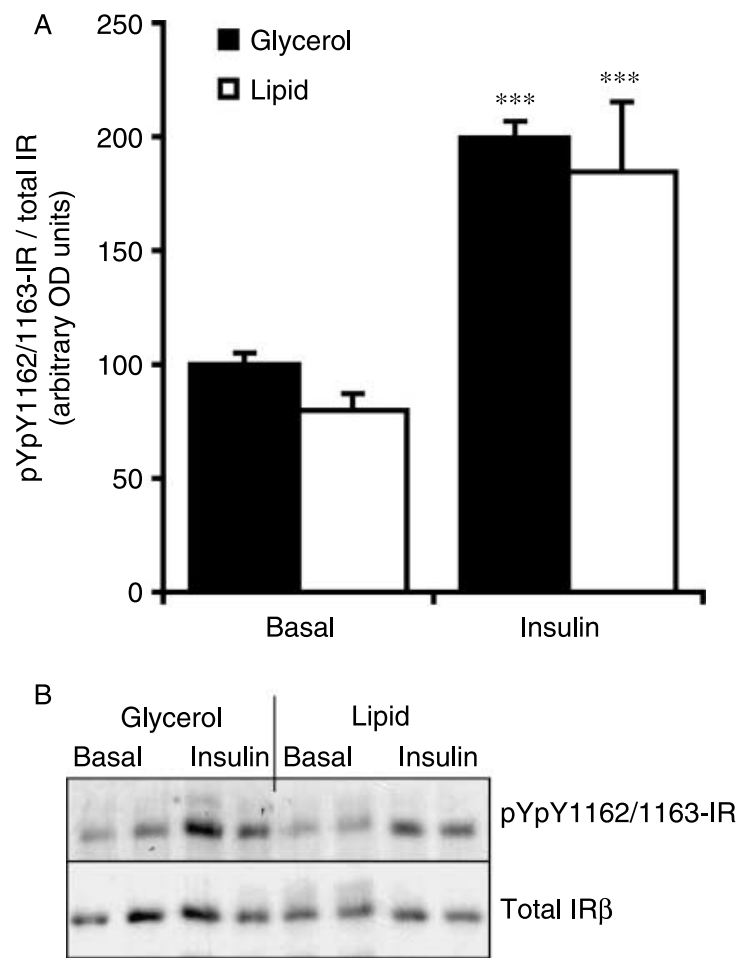

Figure 2 Activation of the insulin receptor by phosphorylation at Tyr1162/1163 in glycerol and lipid-infused rats. Rats were infused with $7 \%$ glycerol or $7 \%$ Intralipid/heparin for $3 \mathrm{~h}$, after which they were either killed (BASAL) or a subset from each group further stimulated with insulin at $0 \cdot 5 \mathrm{U} / \mathrm{kg}$ per $\mathrm{h}$ for $5 \mathrm{~min}$ (INSULIN). Red quadriceps skeletal muscle was collected and western blotting subsequently performed. (A) Quantification of all results.

(B) Representative blots of phosphorylated and total IR $\beta$. Values are mean \pm s.E.M. of $n=6-7$ rats/group. ${ }^{* * *} P<0 \cdot 001$ versus basal.

\section{Activation of IRS-1}

IRS-1 Tyr612 phosphorylation (a PI3-K-binding site; Sun et al. 1993, Esposito et al. 2001) was unchanged with lipid infusion, compared with GLYC infusion, in the basal state (Fig. 3A and B). Insulin infusion caused a two- to threefold increase in skeletal muscle IRS-1 Tyr612 phosphorylation in both the GLYC and lipid-infused rats (Fig. 3A and B). There was no significant difference in the effect of insulin stimulation on IRS-1 at Tyr612 between the GLYC and lipid-infused rat muscle (Fig. 3A and B). Total IRS-1 protein expression was not significantly altered by infusion with GLYC, lipid or insulin (Fig. 3B). Phosphorylation of IRS-1 at the inhibitory Ser307 site was not altered with the $3 \mathrm{~h}$ GLYC or lipid infusion or the additional 5-min insulin infusion (Fig. 3C and D).

\section{PKB phosphorylation}

Phosphorylation of $\mathrm{PKB}$ at the Ser473 residue is required for complete activation of this protein (Alessi et al. 1996, Kandel \& Hay 1999). Basal PKB Ser473 phosphorylation was not statistically different between the GLYC and lipid-infused rats (Fig. 4A and B). Furthermore, while there was a significant 2.4-fold insulin stimulation effect on the GLYC-infused rats, insulin did not elicit a significant effect over basal in the lipidinfused rats (Fig. 4A and B). Therefore, the level of phosphorylation in the insulin-stimulated, lipid-infused rats was significantly lower than that of the insulin-stimulated, GLYC-infused rats. Total PKB protein expression was not significantly modified by the various interventions (Fig. 4B).

\section{GSK3 $\beta$ phosphorylation}

The inactivation of GSK-3 $\beta$ by phosphorylation at the Ser9 residue alleviates its inhibition on the enzyme glycogen synthase, thereby promoting glycogen synthesis as an end point of the insulin signalling pathway (Whiteman et al. 2002). Only the $\beta$-isoform of phosphorylated GSK-3 was detected in our model (Fig. 5B). Basal Ser9-GSK3 $\beta$ phosphorylation was similar in the GLYC and lipid-infused rats (Fig. 5A and B). In line with what was observed the level of PKB, there was a significant $2 \cdot 1$-fold increase in Ser9GSK3 $\beta$ phosphorylation in the insulin-stimulated GLYCinfused rats, compared with only a $44 \%$ non-significant increase in the insulin-stimulated lipid-infused rats, i.e. insulin-stimulated phosphorylation in the lipid-infused rats was significantly lower than that of the GLYC-infused rats (Fig. 5A and B). Total GSK3 $\beta$ protein expression was not significantly changed by the various interventions (Fig. 5B).

\section{Stress signalling}

Activation of the JNK and IKK/NF- $\mathrm{BB}$ stress signalling pathways have recently been implicated in insulin resistance by negatively regulating insulin signal transduction. Thr183/ Tyr185-JNK and total JNK (Fig. 6A and B), as well as 

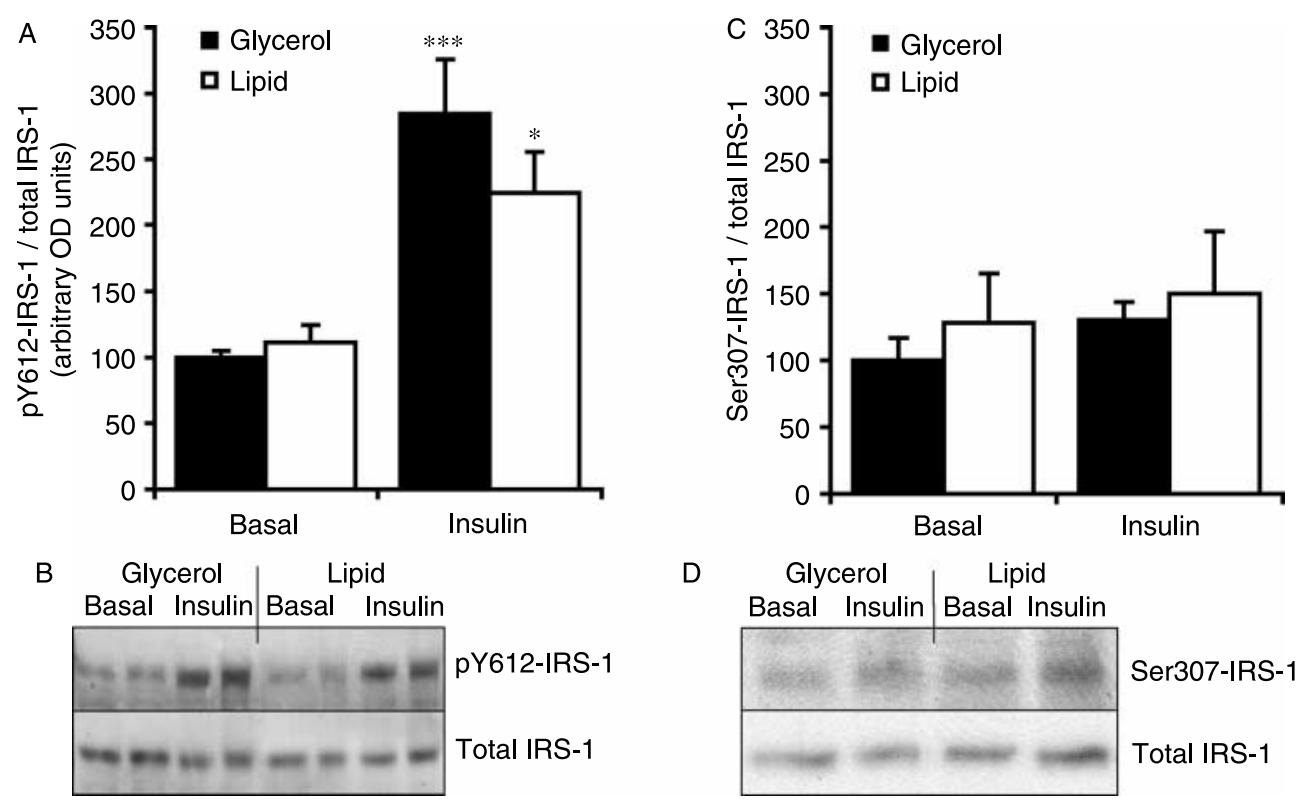

Figure 3 Insulin receptor substrate-1 phosphorylation at Tyr612 and Ser307 in glycerol and lipid-infused rats. Rats were infused with $7 \%$ glycerol or $7 \%$ Intralipid/heparin for $3 \mathrm{~h}$, after which they were either killed (BASAL) or a subset from each group further stimulated with insulin at $0.5 \mathrm{U} / \mathrm{kg}$ per $\mathrm{h}$ for $5 \mathrm{~min}$ (INSULIN). Red quadriceps skeletal muscle was collected and western blotting subsequently performed. (A) Quantification of all results for Tyr612. (B) Representative blots of pY612-phosphorylated and total IRS-1. (C) Quantification of all results for Ser307. (D) Representative blots of Ser307-phosphorylated and total IRS-1. Values are mean \pm S.E.M. of $n=6-7$ rats/group. ${ }^{* * *} P<0 \cdot 001$ and $* P<0 \cdot 05$ versus basal.

Ser32-I $\kappa \mathrm{B} \alpha$ and total $\mathrm{I} \kappa \mathrm{B} \alpha$ (Fig. 7A and B), were not significantly different between the GLYC and lipid-infused rats. Furthermore, Ser176/180-IKK $\beta$ phosphorylation and IKK $\beta$ expression was also not significantly different between groups (data not shown). Consistent with these results, inhibitory Ser307-IRS-1 phosphorylation was not increased in the lipid-infused animals, compared with the GLYCinfused animals (Fig. 3C and D).

\section{Discussion}

Several studies have suggested that the insulin resistance observed in obese or type 2 diabetic humans and diet-induced animal models of insulin resistance can be mimicked by an acute infusion of lipid to produce elevated levels of circulating FA (Boden et al. 1991, Roden et al. 1996, Chalkley et al. 1998). The aim of this study was to assess the effect of an acute, physiological elevation of circulating FA on the initial activation of insulin signal transduction. Insulin and stress signalling was assessed in RQ skeletal muscle, the major target tissue of insulin action. Other studies have demonstrated that similar elevation of FA produces insulin resistance but none have examined the initial signalling events under the same conditions (e.g. Griffin et al. 1999).

The major findings of this study were that altered RQ insulin signalling in this model was observed downstream of the IR and IRS-1, at the level of PKB and GSK-3 $\beta$.
Insulin-stimulated PKB Ser473 and Ser9-GSK3 $\beta$ phosphorylation was reduced in the lipid-infused rats (Figs 4 and 5 respectively), whereas there was no significant impact on insulin-stimulated IR Tyr1162/1163 (Fig. 2) or IRS-1 Tyr612 (Fig. 3A and B) phosphorylation. The reductions seen at the level of insulin-stimulated PKB and GSK3 $\beta$ phosphorylation may have been due to aberrant kinase activities of the proteins themselves, and/or impaired kinase activity of their respective upstream regulatory kinases (e.g. PDK1 for PKB, PKB for GSK $3 \beta$ ), and/or increased serine-threonine phosphatase activity (e.g. PP2A). Examining the regulation of PKB and GSK $3 \beta$ in more detail could form the basis of a follow-up study, to further analyse the roles of PKB and GSK3 $\beta$ in acute lipid-induced insulin resistance.

Unlike other studies, we examined the onset of insulin signalling (with a short and physiological insulin infusion protocol), as this may be more indicative of associated downstream alterations in insulin action. Prolonged insulin infusion during clamps or bolus insulin injections is common, but not necessarily ideal for assessing insulin signalling. This is because down-regulation of the activation state of proteins as a consequence of proteolysis (Takano et al. 2001, Zhande et al. 2002) or secondary changes caused by normal feedback regulation mechanisms (Cohen 1989) can occur within the $1 \cdot 5-2 \mathrm{~h}$ time frame of a clamp and only the maximal capacity of a tissue to respond to insulin can be assessed with bolus injections. It follows then that it is difficult to measure insulin signalling and insulin action in the same animal because the 

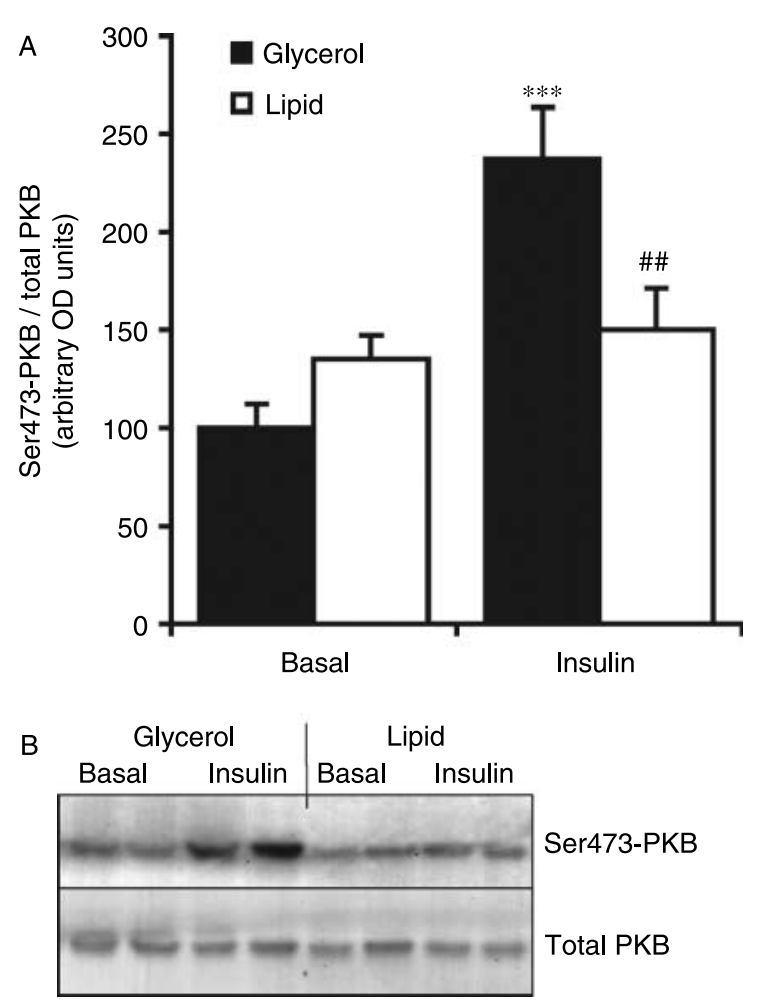

Figure 4 Activation of protein kinase $\mathrm{B}$ by phosphorylation at Ser473 in glycerol and lipid-infused rats. Rats were infused with $7 \%$ glycerol or $7 \%$ Intralipid/heparin for $3 \mathrm{~h}$, after which they were either killed (BASAL) or a subset from each group further stimulated with insulin at $0.5 \mathrm{U} / \mathrm{kg}$ per $\mathrm{h}$ for $5 \mathrm{~min}$ (INSULIN). Red quadriceps skeletal muscle was collected and western blotting subsequently performed. (A) Quantification of all results. (B) Representative blots of phosphorylated and total PKB. Values are mean \pm S.E.M. of $n=6-7$ rats/group. ${ }^{* * *} P<0 \cdot 001$ versus basal; \#\#P<0.01 versus glycerol.

time frame for measuring insulin action $(1-2 \mathrm{~h})$ and insulin signalling (1-10 $\mathrm{min})$ are inherently different.

The differences in insulin signalling reported here, compared with other lipid infusion studies, may also be due to technical differences such as the use of phospho-specific antibodies. Specifically, the lack of effect of lipid infusion on IRS-1 tyrosine phosphorylation reported in this study (Fig. 3A and B) may be because we examined one phospho-tyrosine (pY) site on IRS-1, as opposed to immunoprecipitating IRS-1 and blotting for total $\mathrm{pY}$ as in other studies (Griffin et al. 1999, Kim et al. 2001, Hevener et al. 2002, Yu et al. 2002). However, the pY site that was examined in this study (Tyr612) is a known PI3-K-binding site (Myers et al. 1996) and so the effect seen was pertinent to signalling events specifically related to glucose metabolism. The reduced total IRS-1 tyrosine phosphorylation reported in other studies is not necessarily only related to glucose metabolism, because IRS-1 interacts with a number of other signalling intermediates via various $\mathrm{pY}$ residues and with putative functions in other cellular metabolic events (Sun et al.
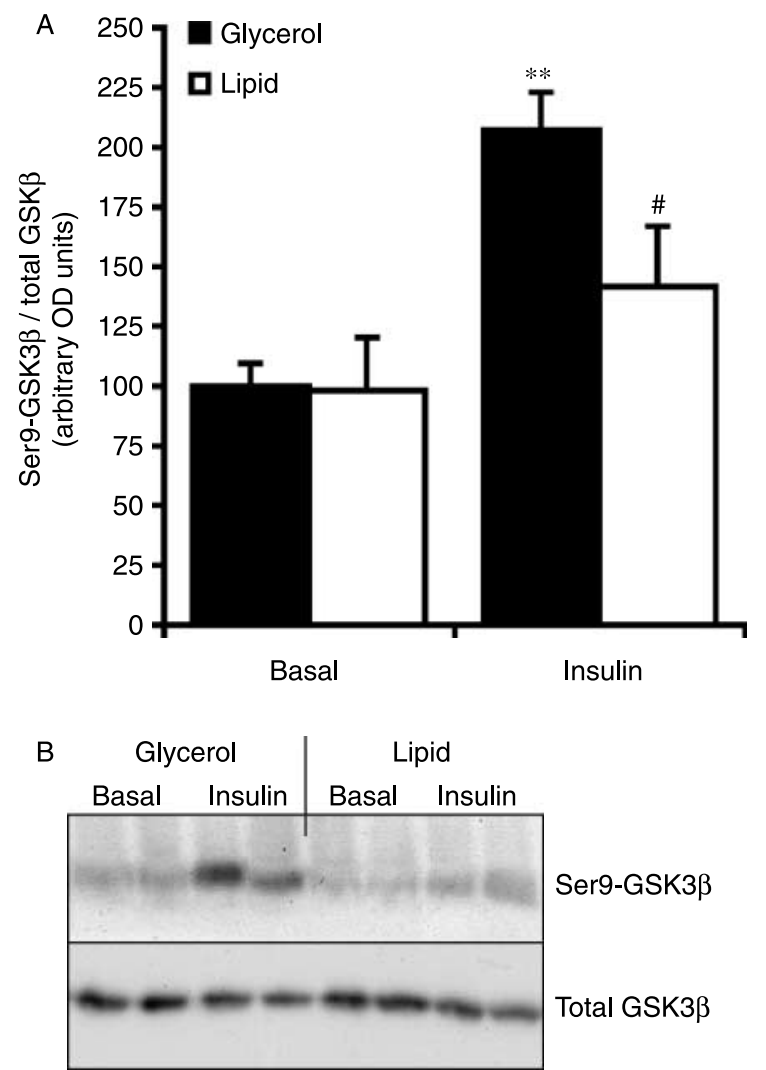

Figure 5 Inactivation of glycogen synthase kinase- $3 \beta$ by phosphorylation at Ser9 in glycerol and lipid-infused rats. Rats were infused with $7 \%$ glycerol or $7 \%$ Intralipid/heparin for $3 \mathrm{~h}$, after which they were either killed (BASAL) or a subset from each group further stimulated with insulin at $0.5 \mathrm{U} / \mathrm{kg}$ per h for $5 \mathrm{~min}$ (INSULIN). Red quadriceps skeletal muscle was collected and western blotting subsequently performed. (A) Quantification of all results. (B) Representative blots of phosphorylated and total GSK3 $\beta$. Values are mean \pm S.E.M. of $n=6-7$ rats/group. ${ }^{* *} P<0 \cdot 01$ versus basal; $\# P<0.05$ versus glycerol.

1995). There are up to 30 potential pY sites on IRS-1 and only six of these are known PI3-K-binding sites (Myers et al. 1996). Results obtained using immunoprecipitation could therefore be confounded by the effect of lipid infusion on $\mathrm{pY}$ residues not necessarily involved in glucose metabolism.

We have recently shown that in RQ of rats fed high-fat diets enriched in either polyunsaturated or saturated fat, both IRS-1 Tyr612 and PKB Ser473 phosphorylation were reduced (Frangioudakis et al. 2005). The effects on insulin signalling with acute lipid infusion differ from those observed with chronic high-fat feeding. This suggests that the underlying mechanisms of impairment in insulin action could be different under situations of acute versus chronic lipid oversupply. These differences may be a consequence of a time-dependent effect of lipid oversupply on insulin signalling, such that elevated circulating FA alone, as was the case in this study, has a different impact compared with the 


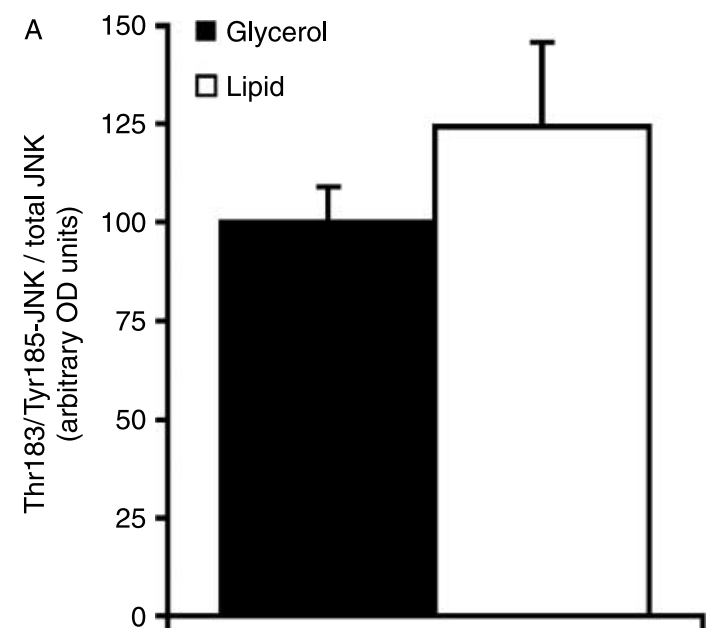

B

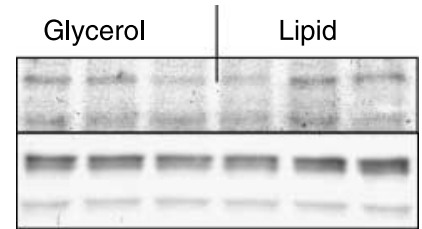

phospho-p54 JNK phospho-p46 JNK

Total JNK2/3

Total JNK1

Figure 6 JNK phosphorylation and total protein expression in glycerol and lipid-infused rats. Rats were infused with $7 \%$ glycerol or $7 \%$ Intralipid/heparin for $3 \mathrm{~h}$, after which they were killed (i.e. BASAL). Red quadriceps skeletal muscle was collected and western blotting subsequently performed. (A) Quantification of all results. (B) Representative blots of phosphorylated and total JNK. Values are mean \pm S.E.M. of $n=6$ rats/group.

longer-term effect of tissue TG accumulation, as seen with chronic high-fat feeding (Frangioudakis et al. 2005). The defect in IRS-1 tyrosine phosphorylation observed in chronic lipid oversupply may therefore be a consequence of a metabolic adaptation of the whole body to surplus lipids, resulting in an enhanced ability to clear FA from the circulation (Hegarty et al. 2002) and increased intracellular metabolites of FA, such as long chain acyl-CoA, diacylglyceride or ceramide, all of which contribute to additional signalling perturbations (Schmitz-Peiffer 2000). The model used in the present study may more appropriately reflect the acute impact of changes in the diurnal FA profile observed in high-fat-fed rats, where circulating FAs are markedly increased during the night-time feeding phase (Stavinoha et al. 2004).

In this study, it appears that stimulation of the JNK and IKK/NF- $\kappa \mathrm{B}$ stress signalling pathways did not occur after $3 \mathrm{~h}$ of increased FA levels. Phosphorylation of major players in these pathways (JNK, IKK $\beta$ and IKB $\alpha$ ) was not affected by lipid infusion. Furthermore, degradation of the inhibitor of NF- $\kappa \mathrm{B}, \mathrm{I} \kappa \mathrm{B} \alpha$, which occurs upon phosphorylation by the IKK complex (and is a commonly used surrogate measure of activation of IKK/NF- $\kappa \mathrm{B}$ signalling in various systems,
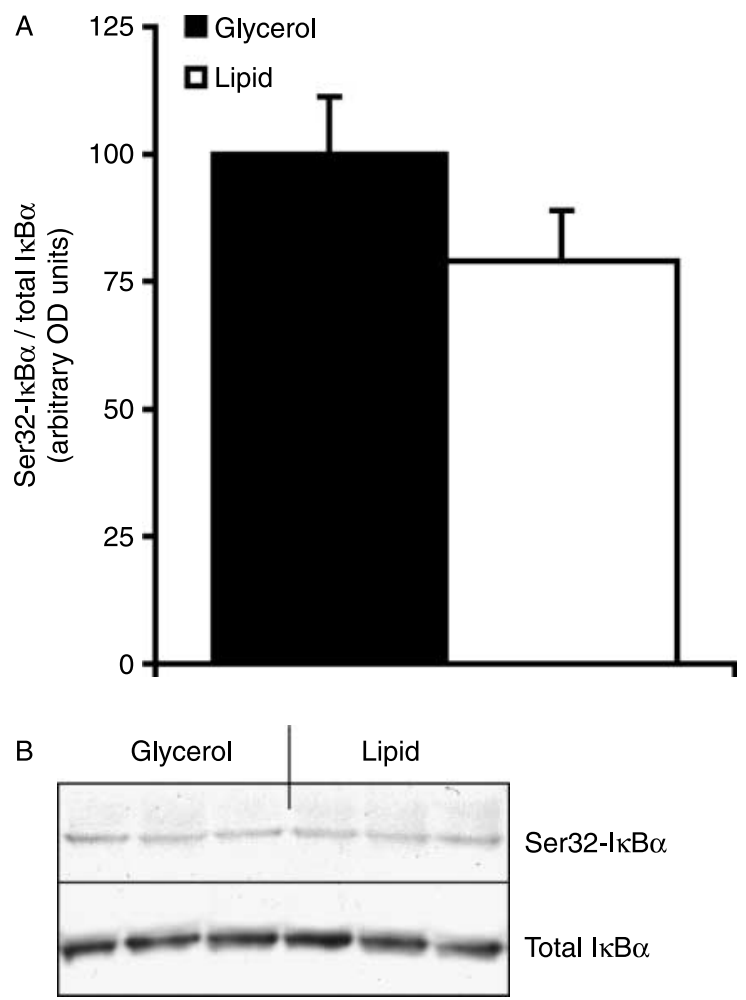

Figure $7 \quad I \kappa B \alpha$ phosphorylation and total protein expression in glycerol and lipid-infused rats. Rats were infused with $7 \%$ glycerol or $7 \%$ Intralipid/heparin for $3 \mathrm{~h}$, after which they were killed (i.e. BASAL). Red quadriceps skeletal muscle was collected and western blotting subsequently performed. Quantification of all results is shown in (A), followed by representative blots of phosphorylated and total $\mathrm{I}_{\mathrm{B}} \mathrm{\alpha} \alpha$ in (B). Values are mean \pm S.E.M. of $n=6$ rats/group.

e.g. in palmitate-incubated L6 myotubes (Sinha et al. 2004) or tumour necrosis factor- $\boldsymbol{\alpha}$-treated HepG2 cells (Gao et al. 2002), was not observed in our in vivo model. This is consistent with no change in phosphorylation at the level of IRS-1 - either reduced activating tyrosine phosphorylation or increased inhibitory serine phosphorylation (Fig. 3). The results from the present study suggest that the activation of stress signalling pathways may not be a significant factor in the initial stages of insulin signalling defects induced by excess FA. In terms of JNK signalling, literature reports suggest that more severe physical insults such as atrophy or eccentric contraction of skeletal muscle result in robust phosphorylation of JNK (e.g. Boppart et al. 1999, Carlson et al. 2001, Martineau \& Gardiner 2001, Hilder et al. 2003). Our comparatively mild intervention of acute lipid infusion may not be sufficiently 'stressful' to lead to activation of such pathways and therefore JNK may not necessarily have a role in the initial stages of FA-induced impairments in insulin signalling. In relation to IKK/NF- $\mathrm{BB}$ signalling, in human muscle biopsies obtained following a lipid infusion that raised circulating FA to $1 \cdot 2 \mathrm{mM}$, I $\mathrm{K} \mathrm{B} \alpha$ protein abundance was only 
found to be reduced after $6 \mathrm{~h}$, but not after $2 \mathrm{~h}$, of lipid infusion (Itani et al. 2002), suggesting that the time frame of lipid oversupply may be an important factor. Furthermore, whether this pathway is relevant in skeletal muscle remains controversial, with conditional disruption of IKK $\beta$ in mouse skeletal muscle failing to prevent obesity-induced insulin resistance (Rohl et al. 2004). The impact of IKK/NF- $\mathrm{BB}$ signalling on insulin action may also be tissue specific, since hepatic (Boden et al. 2005, Cai et al. 2005) and adipocyte (Nguyen et al. 2005) activation of this stress signalling pathway has recently been detected in insulin-resistant conditions.

In conclusion, the results obtained from these studies indicate that acute elevation of FA impacts on insulinstimulated PKB and GSK- $3 \beta$ phosphorylation, before any obvious decrease in tyrosine phosphorylation of IR and IRS-1 at sites specifically involved in insulin signal transduction, or increase in inhibitory serine phosphorylation of IRS-1. There was also no significant activation of JNK and IKK/NF- $\kappa \mathrm{B}$ stress signalling. Although defects in IRS-1 tyrosine phosphorylation may occur with higher FA levels than those used in this study or longer duration of lipid infusion, the present results suggest that defects in insulinstimulated PKB and GSK-3 $\beta$ phosphorylation may be functionally more important in the acute effect of excess FA on insulin action.

\section{Acknowledgements}

We thank Elaine Preston, Donna Wilks and the staff of the Garvan Institute's Biological Testing Facility for expert technical assistance in this study. This study was supported by the National Health and Medical Research Council of Australia and the Diabetes Australia Research Trust. G F was the recipient of an Australian Postgraduate Research Award. The authors declare that there is no conflict of interest that would prejudice the impartiality of this scientific work.

\section{References}

Aguirre V, Uchida T, Yenush L, Davis R \& White MF 2000 The c-Jun $\mathrm{NH}(2)$-terminal kinase promotes insulin resistance during association with insulin receptor substrate-1 and phosphorylation of Ser(307). Journal of Biological Chemistry 275 9047-9054.

Alessi DR, Andjelkovic M, Caudwell B, Cron P, Morrice N, Cohen P \& Hemmings BA 1996 Mechanism of activation of protein kinase B by insulin and IGF-1. EMBO Journal 15 6541-6551.

Boden G, Jadali F, White J, Liang Y, Mozzoli M, Chen X, Coleman E \& Smith C 1991 Effects of fat on insulin-stimulated carbohydrate metabolism in normal men. Journal of Clinical Investigation 88 960-966.

Boden G, She P, Mozzoli M, Cheung P, Gumireddy K, Reddy P, Xiang X, Luo Z \& Ruderman NB 2005 Free fatty acids produce insulin resistance and activate the proinflammatory nuclear factor- $\mathrm{\kappa B}$ pathway in rat liver. Diabetes 54 3458-3465.

Boppart MD, Aronson D, Gibson L, Roubenoff R, Abad LW, Bean J, Goodyear LJ \& Fielding RA 1999 Eccentric exercise markedly increases c-Jun $\mathrm{NH}(2)$-terminal kinase activity in human skeletal muscle. Journal of Applied Physiology 87 1668-1673.
Cai D, Yuan M, Frantz DF, Melendez PA, Hansen L, Lee J \& Shoelson SE 2005 Local and systemic insulin resistance resulting from hepatic activation of IKK- $\beta$ and NF- $\mathrm{\kappa B}$. Nature Medicine 11 183-190.

Carlson CJ, Fan Z, Gordon SE \& Booth FW 2001 Time course of the MAPK and PI3-kinase response within $24 \mathrm{~h}$ of skeletal muscle overload. Journal of Applied Physiology 91 2079-2087.

Chalkley SM, Hettiarachchi M, Chisholm DJ \& Kraegen EW 1998 Five-hour fatty acid elevation increases muscle lipids and impairs glycogen synthesis in the rat. Metabolism 47 1121-1126.

Chen YD, Golay A, Swislocki AL \& Reaven GM 1987 Resistance to insulin suppression of plasma free fatty acid concentrations and insulin stimulation of glucose uptake in noninsulin-dependent diabetes mellitus. Journal of Clinical Endocrinology and Metabolism 64 17-21.

Cohen P 1989 The structure and regulation of protein phosphatases. Annual Review of Biochemistry $\mathbf{5 8}$ 453-508.

Esposito DL, Li Y, Cama A \& Quon MJ $2001 \operatorname{Tyr}(612)$ and Tyr(632) in human insulin receptor substrate-1 are important for full activation of insulinstimulated phosphatidylinositol 3-kinase activity and translocation of GLUT4 in adipose cells. Endocrinology 142 2833-2840.

Folch J, Lees M \& Sloane Stanley GH 1957 A simple method for the isolation and purification of total lipids from animal tissues. Journal of Biological Chemistry 226 497-509.

Frangioudakis G, Ye JM \& Cooney GJ 2005 Both saturated and n-6 polyunsaturated fat diets reduce phosphorylation of insulin receptor substrate- 1 and protein kinase B in muscle during the initial stages of in vivo insulin stimulation. Endocrinology 146 5596-5603.

Fraze E, Donner CC, Swislocki AL, Chiou YA, Chen YD \& Reaven GM 1985 Ambient plasma free fatty acid concentrations in noninsulindependent diabetes mellitus: evidence for insulin resistance. Journal of Clinical Endocrinology and Metabolism 61 807-811.

Gao Z, Hwang D, Bataille F, Lefevre M, York D, Quon MJ \& Ye J 2002 Serine phosphorylation of insulin receptor substrate 1 by inhibitor kappa B kinase complex. Journal of Biological Chemistry 277 48115-48121.

Griffin ME, Marcucci MJ, Cline GW, Bell K, Barucci N, Lee D, Goodyear LJ, Kraegen EW, White MF \& Shulman GI 1999 Free fatty acid-induced insulin resistance is associated with activation of protein kinase $\mathrm{C}$ theta and alterations in the insulin signaling cascade. Diabetes 48 1270-1274.

Hegarty BD, Cooney GJ, Kraegen EW \& Furler SM 2002 Increased efficiency of fatty acid uptake contributes to lipid accumulation in skeletal muscle of high fat-fed insulin-resistant rats. Diabetes 51 1477-1484.

Hevener A, Reichart D, Janez A \& Olefsky J 2002 Female rats do not exhibit free fatty acid-induced insulin resistance. Diabetes 51 1907-1912.

Hilder TL, Tou JC, Grindeland RE, Wade CE \& Graves LM 2003 Phosphorylation of insulin receptor substrate-1 serine 307 correlates with JNK activity in atrophic skeletal muscle. FEBS Letters 553 63-67.

Hirosumi J, Tuncman G, Chang L, Gorgun CZ, Uysal KT, Maeda K, Karin M \& Hotamisligil GS 2002 A central role for JNK in obesity and insulin resistance. Nature 420 333-336.

Itani SI, Ruderman NB, Schmieder F \& Boden G 2002 Lipid-induced insulin resistance in human muscle is associated with changes in diacylglycerol, protein kinase C, and IкB- $\alpha$. Diabetes 51 2005-2011.

Kandel ES \& Hay N 1999 The regulation and activities of the multifunctional serine/threonine kinase Akt/PKB. Experimental Cell Research 253 210-229.

Kim JK, Kim YJ, Fillmore JJ, Chen Y, Moore I, Lee J, Yuan M, Li ZW, Karin M, Perret $\mathrm{P}$ et al. 2001 Prevention of fat-induced insulin resistance by salicylate. Journal of Clinical Investigation 108 437-446.

Kruszynska YT, Worrall DS, Ofrecio J, Frias JP, Macaraeg G \& Olefsky JM 2002 Fatty acid-induced insulin resistance: decreased muscle PI3K activation but unchanged Akt phosphorylation. Journal of Clinical Endocrinology and Metabolism 87 226-234.

Laemmli UK 1970 Cleavage of structural proteins during the assembly of the head of bacteriophage T4. Nature 227 680-685.

Le Marchand-Brustel Y, Gual P, Gremeaux T, Gonzalez T, Barres R \& Tanti JF 2003 Fatty acid-induced insulin resistance: role of insulin receptor substrate 1 serine phosphorylation in the retroregulation of insulin signalling. Biochemical Society Transactions 31 1152-1156. 
Martineau LC \& Gardiner PF 2001 Insight into skeletal muscle mechanotransduction: MAPK activation is quantitatively related to tension. Journal of Applied Physiology 91 693-702.

Matsuzawa Y, Funahashi T \& Nakamura T 1999 Molecular mechanism of metabolic syndrome $\mathrm{X}$ : contribution of adipocytokines adipocyte-derived bioactive substances. Annals of the New York Academy of Sciences $\mathbf{8 9 2}$ 146-154.

Myers MG Jr, Zhang Y, Aldaz GA, Grammer T, Glasheen EM, Yenush L, Wang LM, Sun XJ, Blenis J, Pierce JH et al. 1996 YMXM motifs and signaling by an insulin receptor substrate 1 molecule without tyrosine phosphorylation sites. Molecular and Cellular Biology 16 4147-4155.

Newsholme EA \& Leech AR 1983 Biochemistry for the Medical Sciences., Chichester: John Wiley \& Sons.

Nguyen MT, Satoh H, Favelyukis S, Babendure JL, Imamura T, Sbodio JI, Zalevsky J, Dahiyat BI, Chi NW \& Olefsky JM 2005 JNK and tumor necrosis factor-alpha mediate free fatty acid-induced insulin resistance in 3T3-L1 adipocytes. Journal of Biological Chemistry $28035361-35371$.

Pan DA, Lillioja S, Kriketos AD, Milner MR, Baur LA, Bogardus C, Jenkins AB \& Storlien LH 1997 Skeletal muscle triglyceride levels are inversely related to insulin action. Diabetes 46 983-988.

Roden M, Price TB, Perseghin G, Petersen KF, Rothman DL, Cline GW \& Shulman GI 1996 Mechanism of free fatty acid-induced insulin resistance in humans. Journal of Clinical Investigation 97 2859-2865.

Rohl M, Pasparakis M, Baudler S, Baumgartl J, Gautam D, Huth M, De Lorenzi R, Krone W, Rajewsky K \& Bruning JC 2004 Conditional disruption of I $\kappa-\mathrm{B}$ kinase 2 fails to prevent obesity-induced insulin resistance. Journal of Clinical Investigation 113 474-481.

Schmitz-Peiffer C 2000 Signalling aspects of insulin resistance in skeletal muscle: mechanisms induced by lipid oversupply. Cellular Signalling $\mathbf{1 2}$ 583-594.

Sinha S, Perdomo G, Brown NF \& O'Doherty RM 2004 Fatty acid-induced insulin resistance in L6 myotubes is prevented by inhibition of activation and nuclear localization of nuclear factor $\kappa \mathrm{B}$. Journal of Biological Chemistry 279 41294-41301.

Stavinoha MA, Rayspellicy JW, Hart-Sailors ML, Mersmann HJ, Bray MS \& Young ME 2004 Diurnal variations in the responsiveness of cardiac and skeletal muscle to fatty acids. American Journal of Physiology. Endocrinology and Metabolism 287 E878-E887.

Storlien LH, Jenkins AB, Chisholm DJ, Pascoe WS, Khouri S \& Kraegen EW 1991 Influence of dietary fat composition on development of insulin resistance in rats. Relationship to muscle triglyceride and $\omega-3$ fatty acids in muscle phospholipid. Diabetes 40 280-289.
Sun XJ, Crimmins DL, Myers MG Jr, Miralpeix M \& White MF 1993 Pleiotropic insulin signals are engaged by multisite phosphorylation of IRS-1. Molecular and Cellular Biology 13 7418-7428.

Sun XJ, Wang LM, Zhang Y, Yenush L, Myers MG Jr, Glasheen E, Lane WS, Pierce JH \& White MF 1995 Role of IRS-2 in insulin and cytokine signalling. Nature 377 173-177.

Takano A, Usui I, Haruta T, Kawahara J, Uno T, Iwata M \& Kobayashi M 2001 Mammalian target of rapamycin pathway regulates insulin signaling via subcellular redistribution of insulin receptor substrate 1 and integrates nutritional signals and metabolic signals of insulin. Molecular and Cellular Biology 21 5050-5062.

Tavare JM \& Siddle K 1993 Mutational analysis of insulin receptor function: consensus and controversy. Biochimica et Biophysica Acta 1178 21-39.

Whiteman EL, Cho H \& Birnbaum MJ 2002 Role of Akt/protein kinase B in metabolism. Trends in Endocrinology and Metabolism 13 444-451.

Ye JM, Frangioudakis G, Iglesias MA, Furler SM, Ellis B, Dzamko N, Cooney GJ \& Kraegen EW 2002 Prior thiazolidinedione treatment preserves insulin sensitivity in normal rats during acute fatty acid elevation: role of the liver. Endocrinology 143 4527-4535.

Ye JM, Dzamko N, Cleasby ME, Hegarty BD, Furler SM, Cooney GJ \& Kraegen EW 2004 Direct demonstration of lipid sequestration as a mechanism by which rosiglitazone prevents fatty-acid-induced insulin resistance in the rat: comparison with metformin. Diabetologia 47 1306-1313.

Yu C, Chen Y, Cline GW, Zhang D, Zong H, Wang Y, Bergeron R, Kim JK, Cushman SW, Cooney GJ et al. 2002 Mechanism by which fatty acids inhibit insulin activation of insulin receptor substrate-1 (IRS-1)-associated phosphatidylinositol 3-kinase activity in muscle. Journal of Biological Chemistry 277 50230-50236.

Yuan M, Konstantopoulos N, Lee J, Hansen L, Li ZW, Karin M \& Shoelson SE 2001 Reversal of obesity- and diet-induced insulin resistance with salicylates or targeted disruption of Ikk $\beta$. Science 293 1673-1677.

Zhande R, Mitchell JJ, Wu J \& Sun XJ 2002 Molecular mechanism of insulininduced degradation of insulin receptor substrate 1. Molecular and Cellular Biology 22 1016-1026.

Received in final form 21 February 2008

Accepted 26 February 2008

Made available online as an Accepted Preprint 26 February 2008 